\title{
Mapeamento da língua terena na Aldeia Aldeinha município de Anastácio, MS
}

\author{
Mapping of the terena language in the Aldeia Aldeinha municipality of \\ Anastácio, MS \\ Cartographie de la langue Terena dans la municipalité du Aldeia Aldeinha \\ d'Anastácio, MS \\ Cartografía de la lengua terena en el municipio Aldeia Aldeinha de Anastácio, MS \\ Evelin Tatiane da Silva Pereira* \\ (evelin_hekere@hotmail.com) \\ Elisangela Castedo Maria do Nascimento* \\ (ecmcursino@yahoo.com.br)
}

Recebido em 10/07/2012; revisado e aprovado em 12/11/2012; aceito em 10/12/2012

\begin{abstract}
Resumo: O objetivo dessa pesquisa foi averiguar de que forma a interculturalidade tem interferido sobre costumes tradicionais e sobre o uso da Língua Terena dos indígenas da Aldeia Aldeinha localizada no município de Anastácio, MS. Foram levantadas as causas que levaram ao desinteresse pelo uso da Língua Terena e formas de revitalizá-la, pois, se a língua deixa de ser falada, morre também a história de um povo.

Palavras-chave: Urbanização. Língua terena. Aldeia Aldeinha.

Abstract: The aim of this study was to investigate in order to interculturality has interfered on traditional customs and usage of the language of the indigenous Terena Aldeinha Village located in the municipality of Anastasius, MS. Raised were the causes that led to disinterest in the use of the Terena language and ways of revitalizing it, as if language no longer spoken dies also the story of a people.

Key words: Urbanization. Terena language. Aldeinha Village.

Résumé: Le but de cette étude était d'étudier en vue de l'interculturalité s'est immiscé sur les coutumes traditionnelles et l'utilisation de la langue du village indigènes de Terena Aldeinha situé dans la municipalité d'Anastase, MS. Soulevées étaient les causes qui ont conduit à un désintérêt à l'utilisation de la langue Terena et les moyens de revitaliser, comme si la langue n'est plus parlée meurt aussi l'histoire d'un peuple.

Mots-clés: Urbanisation. La langue terena. Village Aldeinha

Resumen: El objetivo de este estudio fue investigar con el fin de la interculturalidad ha interferido en las costumbres tradicionales y el uso de la lengua de los indígenas del pueblo Terena Aldeinha ubicada en el municipio de Anastasio, MS. Criado fueron las causas que llevaron a la falta de interés en el uso de la lengua Terena y las formas de revitalizar, como si el lenguaje ya no se habla se muere también la historia de un pueblo.

Palabras clave: Urbanización. Terena lengua. Pueblo Aldeinha.
\end{abstract}

\section{Introdução}

Segundo o IBGE (2010), o Brasil possui 817.000 indígenas, cerca de 220 etnias e 180 línguas, sendo o Centro-Oeste a segunda região com maior número perdendo apenas para a região Norte (SOUZA, 2010).
“No Estado do Mato Grosso do Sul, existem várias etnias como: Guarani/Kaiowá, Guató, Terena, Kadiwéu, Ofaié, Atikun e Kinikinau" (BRASIL, 2007). Uma das maiores etnias indígenas do estado é a dos Terena, espalhados pelos municípios de Aquidauana, Anastácio, Miranda Nioaque, Sidrolândia, Dois Irmãos do Buriti e Dourados (Mapa 1).

\footnotetext{
* Universidade Federal do Mato Grosso do Sul.
} 


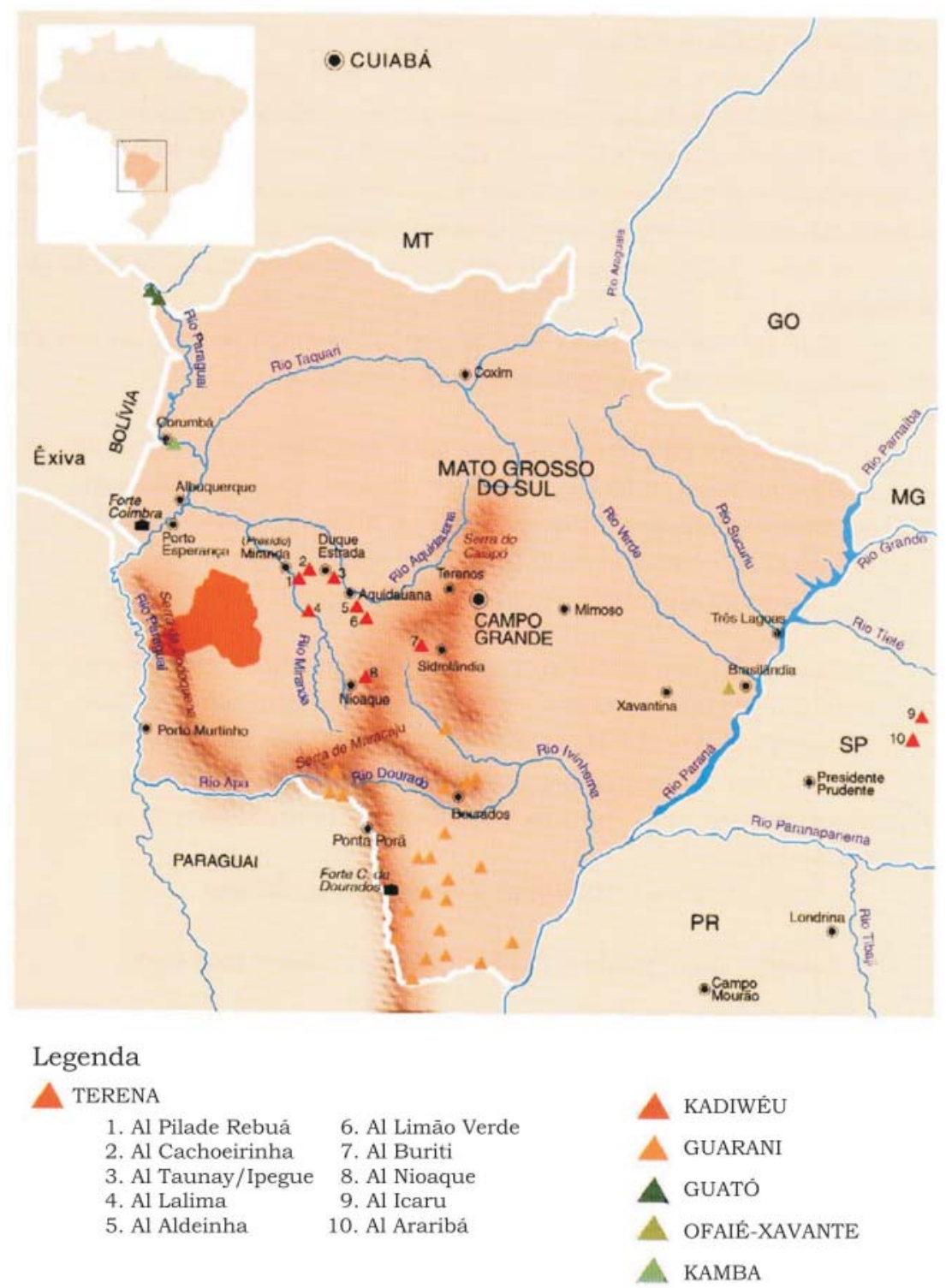

Mapa 1 - A Ocupação indígena em Mato Grosso do Sul.

Fonte: Bittencourt e Ladeira, 2000, p. 40.

Com o avanço da urbanização, miscigenação cultural e crescimento desordenado da sociedade envolvente ao redor do povo indígena, muitos costumes e tradições, a exemplo da aldeia Aldeinha situada no Município de Anastácio, MS, foram sendo deixados de se praticar tais como: danças, culinária, artesanatos e principalmente a Língua Materna. Essa aproximação da cultura do indígena com a cultura do não indígena foi um fator contribuinte, assim como o decrescente uso da Língua Terena.

A observação desses fatos contribuiu para o desenvolvimento da pesquisa que objetivou verificar a frequência de uso da Língua Terena na Aldeia Aldeinha, enfatizan- do o modo e ocasião em que a língua é usada, e o levantamento de ações de revitalização por parte dos moradores ou por pessoas de fora da aldeia.

\section{Fundamentação teórica}

Desde a chegada dos europeus, no Brasil, os povos indígenas tiveram que se adaptar ao processo de colonização como, por exemplo, em relação às vestes e à aprendizagem obrigatória da língua portuguesa, suplantando a língua Tupi Guarani.

Os indígenas começaram a aprender a Língua Portuguesa com os jesuítas por 
meio da catequese, e de lá para cá começou o declínio do uso da Língua Tupi. A língua é a identidade do povo e deve ser mantida, assim como sua cultura. A língua indígena foi aproveitada na exploração das terras brasileiras e na evangelização. Por meio do cooperativismo, os jesuítas aprenderam a língua dos indígenas ajudando a desbravar o território e a nomear plantas, animais, entre outras coisas desconhecidas pelos novos moradores neste continente (MELO, 1981).

Em função de muitas perdas durante o processo de colonização, hoje o governo brasileiro reconhece e devolve aos povos indígenas direitos garantidos na Constituição Brasileira de 1988, no Artigo 231. Embora a lei assegure a autonomia dos povos indígenas em relação à cultura, a tradições e uso da língua materna, na prática, o indígena ainda continua sendo alvo de preconceito na sociedade, sendo taxados como alcoólatras, preguiçosos, suicidas, estupradores e bugres. O preconceito talvez seja um dos motivos da não utilização da língua materna e da não prática da cultura indígena pelos jovens na aldeia, na tentativa de serem aceitos pela sociedade envolvente, como verificado nas entrevistas.

Outro fator histórico que influenciou a cultura e contribuiu para perda de território foi a Guerra do Paraguai (1864-1870). Com a guerra, houve perda da maior parte do território Terena para não indígenas (BITTENCOURT; LADEIRA, 2000).

Vargas (2008) comenta sobre o conceito de territorialidade para o Terena. Segundo a autora, a população tem que se sentir parte do território, conservar o lugar em que nasceu, criar um elo com sua terra. Todo ser humano valoriza o lugar onde nasceu e criou raízes, seja ele no urbano ou no rural. Hoje muitas aldeias se encontram cercadas por grandes fazendas onde o espaço já não é tão grande para cultivo de subsistência. A pequena produção colhida está sendo levada para a cidade, onde é vendida de porta em porta ou em lugares determinados, como feira dos índios, como ocorre com os indígenas da aldeia Limão Verde no município de Aquidauana, MS.

Percebe-se que, além da interferência da sociedade envolvente, o próprio indígena Terena tem sua parcela de culpa quando migra de cidade em cidade, não valorizando a terra, abandonando sua aldeia de origem em busca de uma nova forma de vida, deixando de passar para as gerações seguintes a sua cultura e a lembrança de quem realmente é, como tentativa de preservar sua raiz cultural.

Em relação a isso, Limbert (2009, p. 26) comenta: "são índias com calça de braguilha e índios de tênis, calção e colar. Descaracterizados, só lhe restaram de genuínas a aparência física (herança genética) e a língua (herança cultural)", ou seja, tanto os Terena como outras etnias passam pelo processo de descaracterização, em função do não exercer sua cultura, o risco é o de sobrar apenas a semelhança genética como lembrança.

Dessa forma, um dos aspectos mais fortes que contribuíram para que os indígenas deixassem de falar a língua materna foi a questão territorial que, consequentemente, levou à miscigenação cultural. É natural que, no decorrer dos anos, a sociedade passe por mudanças em seu cotidiano uma vez que a cultura é dinâmica. Mas essas mudanças trazem aspectos negativos como a vergonha de falar Língua Terena, e a não prática da cultura indígena pelos jovens da aldeia Aldeinha.

Segundo Maria (2011, p. 28), "as sociedades indígenas são ágrafas. Por não possuírem a escrita alfabética, transmitiam seus conhecimentos e saberes através da oralidade, contando histórias, comunicando e perpetuando a herança cultural de geração em geração". Mas os indígenas jovens da Aldeinha, de certa forma, se sentem acanhados em falar a Língua Terena, como apontado no questionário aplicado na comunidade. Até mesmo o fato de não ter uma família falante contribuiu para que eles não falem a língua materna.

Segundo a Constituição Brasileira de 1988, em seu artigo $210^{\prime \prime}$ [...] é assegurada às comunidades indígenas [...] a utilização de suas línguas maternas e processos próprios de aprendizagem". Dessa forma, é assegurado o direito aos indígenas de manter todas as suas tradições e sua língua por meio do ensino escolar e, portanto, se faz necessária a motivação, a luta pela valorização de nossas tradições e a revitalização da língua materna.

\section{Caracterização do local da pesquisa}

A Aldeia Aldeinha possui 80 residências e um total de 321 moradores, segundo a FUNASA (BRASIL, 2010). Localizada no 
município de Anastácio, a $127 \mathrm{~km}$ de Campo Grande, capital do estado de Mato Grosso do Sul, região Centro-Oeste (IBGE, 2010), a aldeia se encontra em contexto urbano em função do crescimento e avanço desordenado da população Anastaciana, e também em função da não demarcação de terras, fato esse que vem interferindo no uso cotidiano da Língua Terena e alterando o espaço físico e cultural.

Nascida no município de Aquidauana e residente no município de Anastácio na aldeia Aldeinha, eu, Évelin Tatiane da Silva Pereira, autora desta pesquisa pertenço à etnia Terena. Em minha família, apenas meu pai, Carlos Pereira, e minha avó, Vitalina Pereira, são falantes fluentes da língua materna. Assim como eu, existem mais jovens da comunidade na mesma situação de não falantes.

Esse fato levou-me a querer investigar as causas da não utilização da língua materna, assim como, o número de indígenas fluentes na Língua Terena na Aldeia Aldeinha.

\subsection{Histórico da Aldeia Aldeinha (História oral, entrevista in loco)}

Segundo Gedeão Jorge (Professor de Geografia da "Escola Estadual Indígena Guilhermina da Silva"), a chegada da Família da Dona Umbelina Jorge (composta por doze membros) vindo da Aldeia Buriti ocorreu por volta do dia 8 de Abril de 1932, e o motivo foi um desentendimento religioso. A caravana tinha como destino a Aldeia Cachoeirinha no Município de Miranda, MS. Ao chegar à margem esquerda do Rio Aquidauana, atual Anastácio, na fazenda Santa Maria, encontraram o filho da Dona Umbelina, Jorge José da Costa, popularmente conhecido como José Correiro ou Zé Correiro, que pediu de que eles ficassem por aqui mesmo, visto que iria comprar terras na margem esquerda.

O senhor Manequinho, fazendeiro e pai de criação do senhor Zé Correiro, conversaram e fizeram um acordo para comprar 32 hectares de terras (mapa 2) pagos em animais, serviços e retirada de madeira como postes e lenhas para serem usadas na fazenda.

Foi nesta área que a família de dona Umbelina foi instalada, construíram um casebre e fizeram plantações onde toda a família cultivava produtos para a subsistência.
A respeito do nome "Aldeinha", este surgiu por meio dos evangélicos, que, aos domingos após a escola dominical, combinavam visitas aos irmãos da Aldeia pequena se referindo à família de dona Umbelina e seu Zé Correiro, surgindo assim o nome Aldeinha.

O Senhor Elias Nimbú, hoje um dos mais antigos moradores da aldeia, em entrevista, conta que chegou à Aldeinha na década de 60, vindo com sua família do Município de Miranda (Aldeia Moreira) ainda menino. Seu pai, Antônio Nimbú, se comoveu com a situação dos patrícios, que, naquela época, eram cerca de 10 (dez) famílias, sem um chefe de posto para garantir a documentação indígena.

Ele viajava de bicicleta até a Aldeia Limão Verde, em Aquidauana, MS, na tentativa de agilizar e montar um conselho tribal. Nessa época, o município de Anastácio, então chamado margem esquerda do rio Aquidauana, não era emancipado. Apenas em 1982, a primeira liderança foi organizada, tendo como líder o senhor Isaias Delgado.

Juntamente com a criação do conselho tribal, houve a necessidade de revitalizar os costumes terenas já quase deixados de lado em virtude da prática de atividades não indígenas. Pensando na revitalização da cultura, algumas pessoas da Aldeia Limão Verde, como o senhor Adão e senhor Ary, foram convidados a ajudar na formação dos grupos de dança de homens, mulheres e crianças.

A senhora Dirce Francisco conta, em entrevista, que veio quando moça, da Aldeia Córrego Seco, município de Aquidauana, para trabalhar como doméstica nas casas de famílias próximas a Aldeinha no final da década de 80, para conseguir construir uma pequena casa. Junto com seu esposo, Márcio, ajudava na disseminação da tradição Terena por meio de grupos de dança com crianças, jovens e adultos, além de confecção dos trajes nativos, flechas, arcos e lanças.

No mandato do Cacique Pedro Jorge (in memoriam), na década de 90, segundo cacique da aldeia Aldeinha, aconteceram vários fatos que contribuíram contra o trabalho de revitalização da cultura Terena como, por exemplo, a questão de território.

Houve uma invasão dos pernambucanos para a ocupação do território pertencente à comunidade indígena Aldeinha. $\mathrm{O}$ processo 
de defesa do território e resistência contra essa invasão foi difícil, pois os indígenas só possuíam como armas paus e pedras enquanto os pernambucanos tinham armas de fogo.

A partir dessa tomada de terras indígenas pelos não indígenas, iniciou-se, ao redor do povo indígena da aldeia aldeinha, o crescimento urbano e, com isso, os confrontos culturais. Ainda na gestão do Cacique Pedro Jorge, os indígenas conseguiram reaver alguns dos lotes então tomados, recuperando, dessa forma, parte do território (mapa, 3).

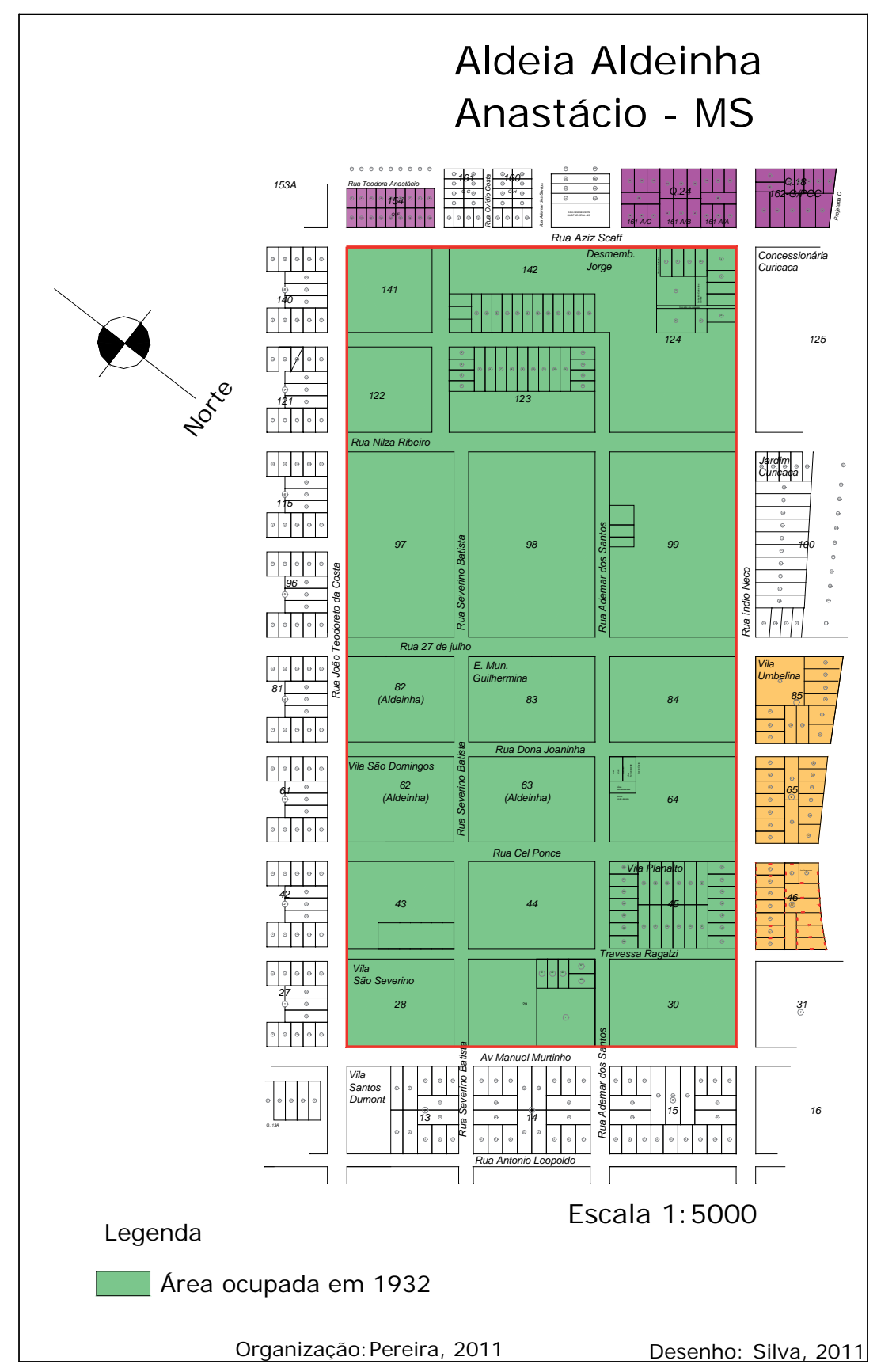

Mapa 2 - Área ocupada em 1932: Aldeia Aldeinha, município de Anastácio, MS 


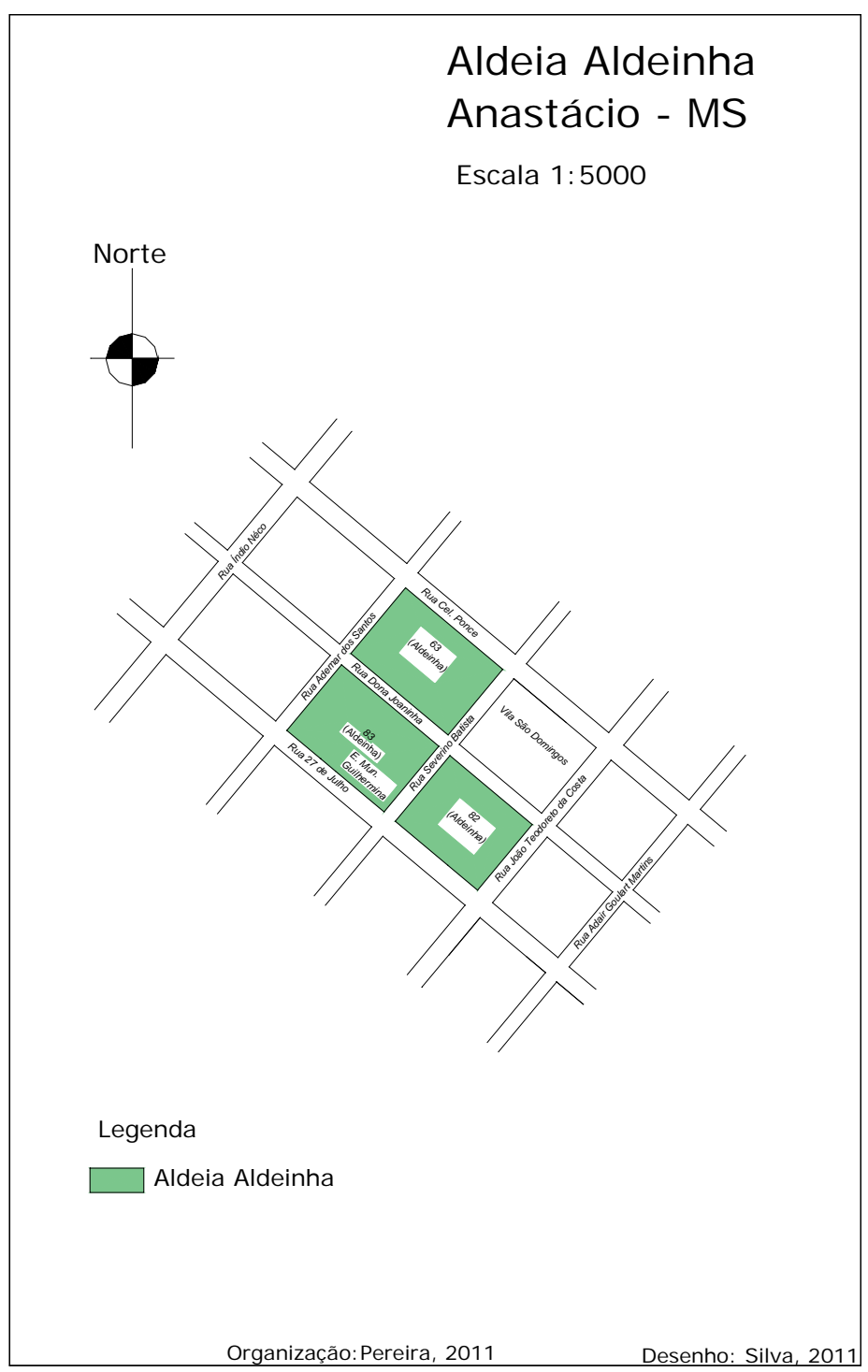

Mapa 3 - Área ocupada em 2011: Aldeia Aldeinha, município de Anastácio, MS

Por meio da comparação desses dois mapas, pode-se perceber a redução drástica do território dos indígenas da Aldeia Aldeinha, assim como a sua condição de sitiada pela sociedade envolvente.

\section{Metodologia}

A pesquisa foi dividida em três etapas:

1) Coleta de informações sobre os moradores da Aldeia Aldeinha, utilizando levantamento bibliográfico e entrevistas;

2) Visita a campo para a aplicação de questionário com os moradores

3) Montagem e interpretação de gráficos com os dados obtidos através do questionário com a intenção de:
- Descrever o perfil desses indígenas da Aldeia Aldeinha;

- Verificar como é o modo de vida já que é uma aldeia localizada no centro urbano;

- Verificar o espaço/área que a aldeia Aldeinha ocupa dentro do município de Anastácio, MS;

- Identificar a origem dos primeiros indígenas;

- Analisar a importância da Língua Materna para o Terena.

A fundamentação teórica foi baseada nos autores Bittencourt, Ladeira (2000), Oliveira (1976), entre outros.

Ludke e André (1986), Lakatos e Marconi (1988) foram utilizados como subsídios na construção da metodologia. Segundo Ludke 
e André (1986), a pesquisa qualitativa prevê um contato direto do pesquisador com o meio e com a situação investigada, além de o material coletado ser rico em descrições, incluindo transcrições de entrevistas e depoimentos, e outros tipos de documentos, na tentativa de reproduzir a história do Povo Terena. Trata-se, portanto, de um estudo de caso, porque visa à descoberta, à interpretação em contexto, buscando retratar a realidade completa e profunda (LUDKE; ANDRÉ, 1986).

\section{Resultados}

Para o levantamento de dados, foi realizada uma pesquisa de campo na Aldeia Aldeinha com visita aleatória aos domicílios para a aplicação dos questionários. Abaixo se encontra a tabulação dos resultados das entrevistas, apresentados em gráficos.

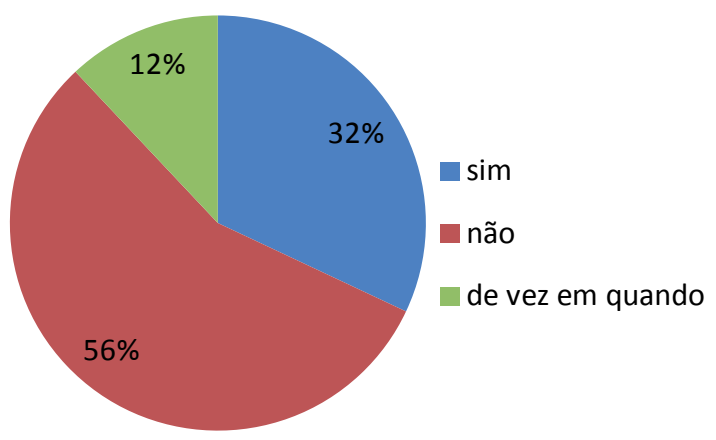

Gráfico1 - Fala ou escreve a língua terena? Fonte: Pereira, 2009.

Apesar de a aldeia ter uma escola indígena com uma disciplina específica de Língua Materna, a maioria não a fala, nem escreve. Os moradores reclamaram da falta de um (a) professor (a) capacitado (a) para essa disciplina. Das cinquenta (50) pessoas entrevistadas, 16 pessoas falam ou escrevem Terena, 28 não falam e/ou escrevem e 06 pessoas falam e/ ou escrevem de vez em quando.

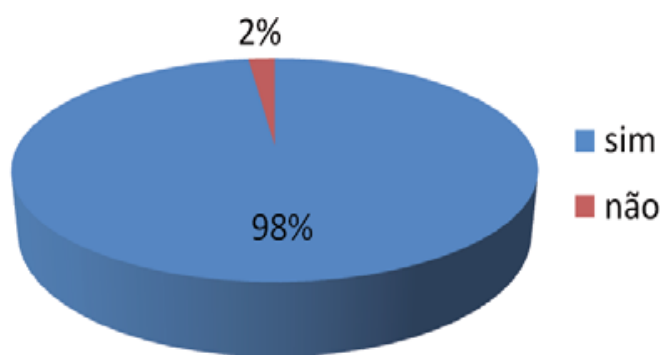

Gráfico 2 - Gosta do idioma Terena? Fonte: PEREIRA, 2009.
Apesar de a maioria gostar do Idioma Terena, a maioria não o fala. Das 50 pessoas entrevistadas, 49 disseram gostar do Idioma Terena e apenas 01 afirmou não gostar.

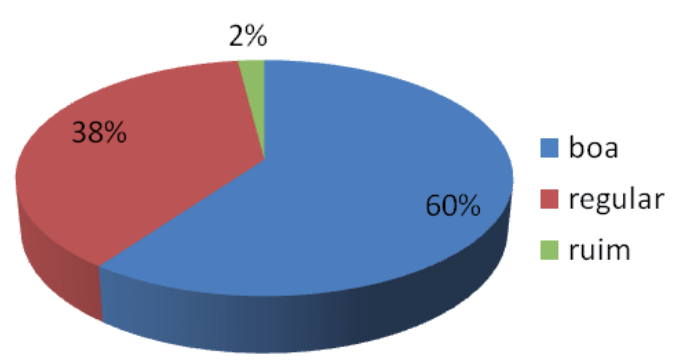

Gráfico 3 - O que acha da localização da Aldeia em que vive?

Fonte: Pereira, 2009.

Das 50 pessoas entrevistadas, 30 delas consideram boa a localização, 19 pessoas acham-na regular e uma pessoa a considera ruim. A maior parte dos domicílios visitados considera como boa a localização da Aldeia devido à proximidade com as casas comerciais, posto de saúde, farmácia e pelo fato de algumas ruas da Aldeia já possuírem rede de esgoto.

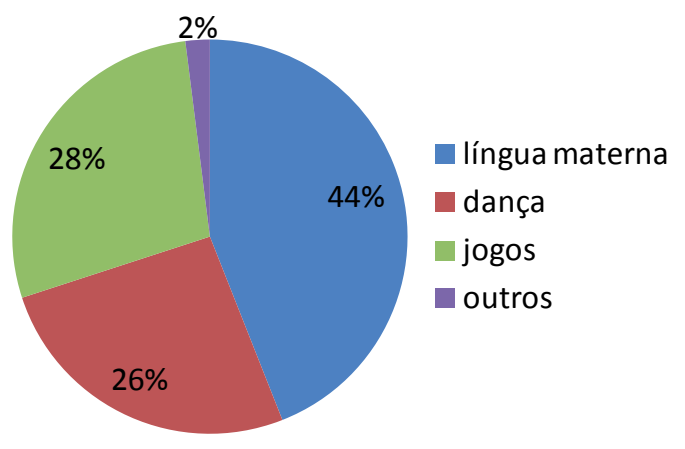

Gráfico 4 - Para você o que é mais importante em nossa Aldeia?

Fonte: Pereira, 2009.

Dentre os entrevistados, 23 pessoas disseram que a Língua Materna é mais importante, 13 preferiram as danças que são praticadas na Semana do Índio, e 14 optaram pelos jogos que são realizados periodicamente na quadra escolar e no campo de futebol. Surgiram outras respostas apontando a religião, os cultos e congressos predominantemente evangélicos. 


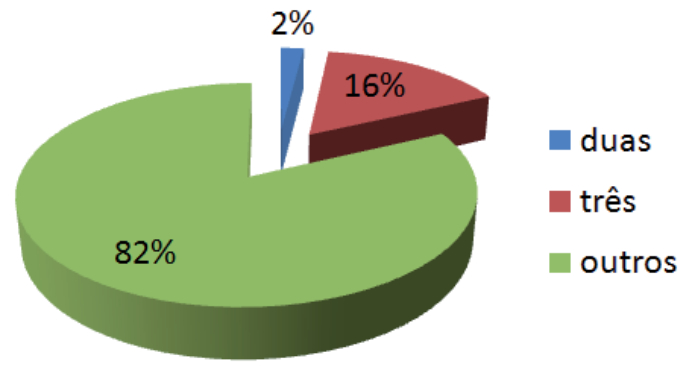

Gráfico 5 - Quantas pessoas moram nessa residência?

Fonte: Pereira, 2009.

É importante destacar o número de integrantes das famílias visitadas na Aldeia Aldeinha, pois é da cultura do indígena ter famílias com grande número de filhos. Uma pessoa entrevistada respondeu ter duas pessoas na casa, 08 pessoas disseram ter três, e 41 pessoas responderam outros, no caso mais de quatro integrantes na casa.

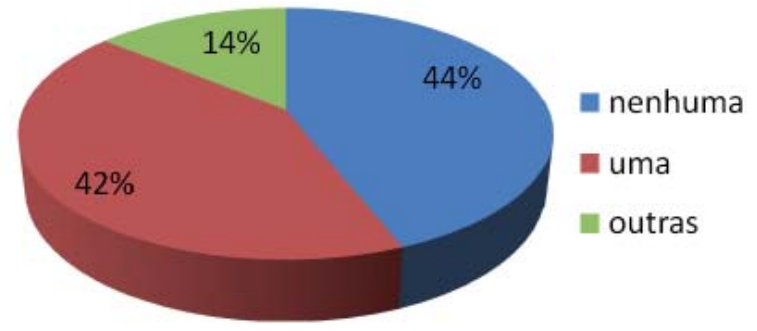

Gráfico 6 - Quem é falante do Idioma Terena na Aldeia?

Fonte: Pereira, 2009.
Entre as 50 pessoas entrevistadas, 07 (sete) eram as pessoas mais idosas da Aldeia e que falavam fluentemente a Língua Terena. Por meio dos Gráficos 06 e 07, pode-se observar que a maior parte dos moradores já não fala o Idioma Terena. As pessoas que ainda falam a língua Terena são os mais velhos (anciãos), que ainda tentam ensinar para as crianças da Aldeinha.

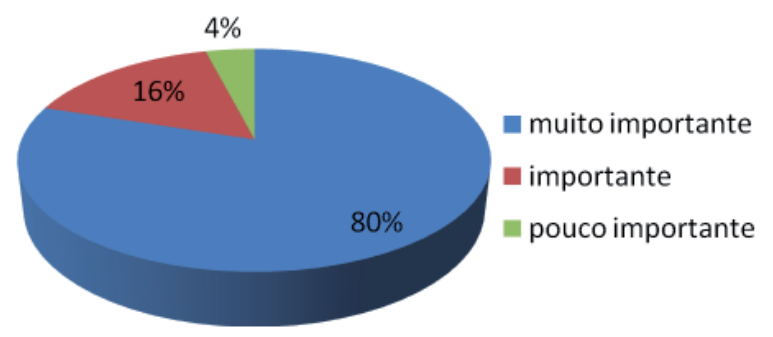

Gráfico 7 - Importância da Língua Materna para o fortalecimento da Etnia Terena: Fonte: Pereira, 2009.

Dentre os entrevistados, 40 (quarenta) pessoas consideram a Língua muito importante, 08 (oito) importante, 02 (duas) pouco importante. O fortalecimento da cultura Terena por meio da Língua é considerado importante na opinião da maioria dos moradores, mas não é ensinada pelos pais aos seus filhos. Dessa forma, as respostas contradizem a ação.

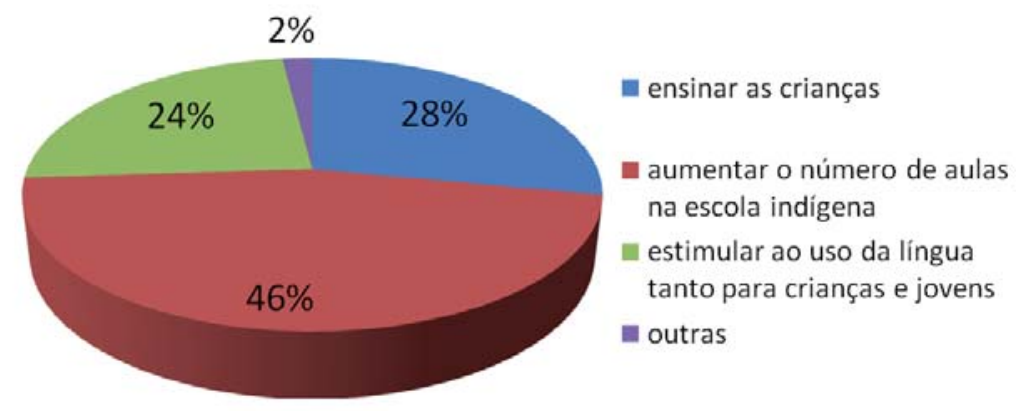

Gráfico 8 - Qual seria a melhor forma para recuperar o Idioma Terena? Fonte: Pereira, 2009.

Em relação ao ensino da Língua, 23 pessoas consideram que se deva aumentar o número de aulas na escola Indígena, 14 acham que se devem ensinar as crianças em casa, 12 acreditam que é preciso estimular a juventude da Aldeia e uma acha que se deve pensar em outras formas de ensinar a Língua Terena. A escola indígena é a opção mais indicada pelos moradores da Aldeia Aldeinha para tentar revitalizar o Idioma, mas não se pode esquecer que a escola da Aldeia também atende as crianças não indígenas, de modo que estas teriam que aprender a Língua Terena. Em segundo lugar, aparece o ensino às crianças pela família. 


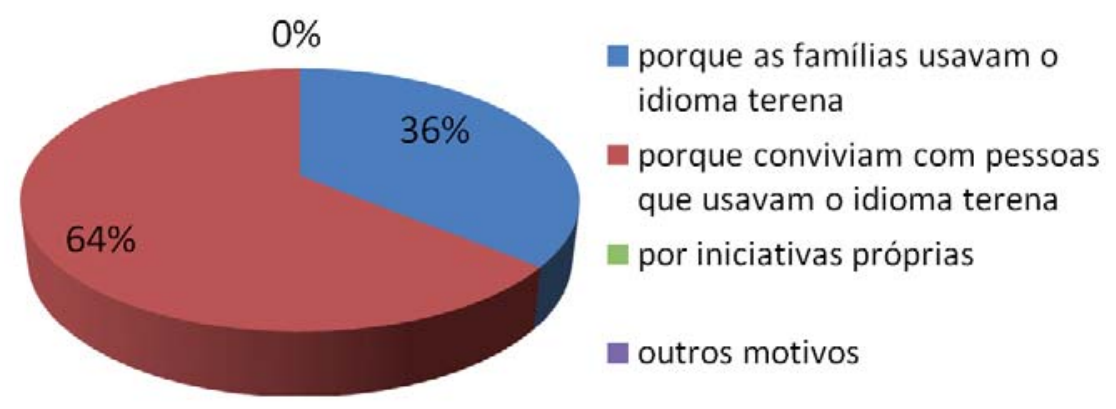

Gráfico 9 - Por que só algumas pessoas falam o Idioma Terena? Fonte: Pereira, 2009.

A existência de indígenas de outras aldeias fluentes da Língua Terena ajudou, mesmo que de forma precária, a manter ainda viva a Língua na Aldeinha. O gráfico mostra que a maioria das pessoas (32) considera o convívio com pessoas falantes, como difusor da língua, porém 18 pessoas apontam para as conversas diárias como tradição entre as famílias, como forma de difundir a língua.

\section{Considerações finais}

A pesquisa apontou que a Língua está sendo deixada de ser usada devido ao crescimento da população Anastaciana ao redor da Aldeia Aldeinha, que sobreviveu e sobrevive sitiada por não indígenas, num constante confronto cultural e na qual atualmente somente os anciãos falam a Língua Terena.

No caso dos Jovens, foi relatado, durante as entrevistas, que muitos têm vergonha da Língua e da cultura, pois se sentem discriminados pela população não indígena, o que agrava ainda mais o processo de desuso da língua. Em muitos casos, os pais já não são falantes, e o que aprendem na escola é esquecido, por não ter com quem praticar em casa.

Hoje, muitos obstáculos na educação estão sendo superados com apoio governamental, está havendo uma valorização linguística no ensino Terena, pois agora existe auxílio de cartilhas para as crianças dos anos iniciais, elaboradas pelos educadores mais idosos da comunidade que falam e escrevem em Terena. Não se pode deixar de dizer o quanto isso é importante porque existe, de aldeia para aldeia, uma variação na escrita ou na pronúncia da Língua Terena.
Quanto à proposta de revitalização da Língua Terena, a pesquisa apontou para formação grupos de estudos após as aulas de Língua Materna (como se fosse um reforço na língua) para os jovens, crianças, comunidade e/ou pessoas interessadas. Mas, para tal proposta tornar-se realidade, faz necessário total apoio da liderança e da comunidade.

É importante deixar registrado que o desenvolvimento desta pesquisa só foi possível por meio do apoio do conselho tribal, que são as pessoas fluentes na língua Terena, e das famílias da Aldeia Aldeinha que participaram da pesquisa com espontaneidade.

Esse trabalho é apenas o início de um trabalho de revitalização da cultura indígena na Aldeia Aldeinha. Há necessidade de um estudo mais aprofundado sobre território e Língua Terena, com o objetivo de identificar as reais dimensões territoriais dos Terenas da Aldeia Aldeinha, além de analisar as formas de pronúncia e escrita para, em um segundo momento, dinamizar as propostas aqui levantadas.

Ensinar o resgate da nossa cultura é preparar o povo, principalmente as crianças para o amanhã [...] Portanto não devemos esquecer as nossas origens. É preciso ter jogo de cintura para fazer as duas coisas: a tradição da cultura e a parte não indígena. A nossa identidade é um conjunto. O nosso objetivo é pelo nosso povo, nossa luta. (ValmorVehrá Mendes de Paula, Professor Kaingang).

\section{Referências}

BITTENCOURT, Circe Maria; LADEIRA, Maria Elisa. A história do povo Terena. São Paulo: USP/Ministério da Educação, Maio/2000. 
BRASIL. Constituição Brasileira de 1988, 1988.

Instituto Brasileiro de Geografia e Estatística (IBGE), 2010.

Ministério da Saúde. Fundação Nacional da Saúde. Relatório Anual, 2007.

Ministério da Saúde. Fundação Nacional da Saúde. Relatório Anual, 2010.

INSTITUTO BRASILEIRO DE GEOGRAFIA E ESTATÍSTICA (IBGE). Mato Grosso do Sul, 2010. Disponível em: <http://ibge.gov.br/home/presidencia/noticias/ pdf/quadro_vagas_ms.pdf>. Acesso em: 02 set. 2012.

LAKATOS, Eva Maria; MARCONI, Marina de Andrade. Fundamentos de metodologia científica. 3. ed. São Paulo: Atlas, 1988.

LIMBERTI, Rita de Cássia Pacheco. Discurso indígena: aculturação e polifonia. Dourados, MS: UFGD, 2009.

LÜDKE, Menga; ANDRÉ, Marli. Pesquisa em educação: abordagens qualitativas. São Paulo: EPU, 1986.

MARIA, E. C. Entrelaçando conhecimentos e saberes: educação ambiental na Escola Indígena Marcolino Lili - Aquidauana-MS. Dissertação (Mestrado em Ensino de Ciências) - Universidade Federal de Mato Grosso do Sul, Campo Grande, 2011.

MELO, Glasdstone Chaves de. A língua do Brasil. 4. ed. Rio de Janeiro: Padrão, 1981.

OLIVEIRA, Roberto Cardoso. Do índio ao bugre: o processo de assimilação dos Terena. 2. ed. Rio de Janeiro: Francisco Alves, 1976.

PEREIRA, Antonia Alves. Estudo morfossintático do Asuriní do Xingu. 2009. 348f. Tese (Doutorado em Linguística) - Universidade Estadual de Campinas, Campinas, SP, 2009.

SOUZA, I. Povos Indígenas e a diversidade linguística. Diversidade cultural: plurilinguísmo, línguas indígenas no Brasil e em Mato Grosso do Sul. In: URQUIZA, Antônio H. A. (Org.). Conhecendo os povos indígenas no Brasil contemporâneo. Coordenadoria de Educação Aberta e a Distância. Módulo 2. Marcos conceituais referentes à diversidade sociocultural. Campo Grande, MS: UFMS, 2010.

VARGAS. I. A. Territorialidade e representação dos Terenas da Terra Indígena Buriti (MS) - possibilidades didáticos pedagógicos. In: SERPA, A. (Org.). Espaços culturais: vivências, imigrações e representações. Salvador: EDUFBA, 2008. 